\title{
Effect of Ce Content on Microstructure-Toughness Relationship in the Simulated Coarse-Grained Heat-Affected Zone of High-Strength Low-Alloy Steels
}

\author{
Yuxin Cao ${ }^{1,2}$, Xiangliang Wan ${ }^{2,3, *}$, Feng Zhou ${ }^{3, *}$, Yong Wang ${ }^{1}$, Xinbin Liu ${ }^{1}$, Kaiming $\mathrm{Wu}^{2}$ and Guangqiang $\mathrm{Li}^{2}{ }^{2}$ \\ 1 School of Intelligent Manufacturing and Mechanical Engineering, Hunan Institute of Technology, \\ Henyang 421002, China; caoyuxin@hnit.edu.cn (Y.C.); wangyong@hnit.edu.cn (Y.W.); \\ liuxinbin@hnit.edu.cn (X.L.) \\ 2 The State Key Laboratory of Refractories and Metallurgy, Wuhan University of Science and Technology, \\ Wuhan 430081, China; wukaiming@wust.edu.cn (K.W.); liguangqiang@wust.edu.cn (G.L.) \\ 3 School of Mechanical and Electrical Engineering, Foshan Polytechnic, Foshan 528237, China \\ * Correspondence: wanxiangliang@wust.edu.cn (X.W.); whzf1234@fspt.edu.cn (F.Z.)
}

check for updates

Citation: Cao, Y.; Wan, X.; Zhou, F.; Wang, Y.; Liu, X.; Wu, K.; Li, G. Effect of Ce Content on Microstructure-

Toughness Relationship in the Simulated Coarse-Grained Heat-Affected Zone of High-Strength Low-Alloy Steels. Metals 2021, 11 , 2003. https://doi.org/10.3390/ met11122003

Academic Editor: Marcello Cabibbo

Received: 20 October 2021

Accepted: 7 December 2021

Published: 11 December 2021

Publisher's Note: MDPI stays neutral with regard to jurisdictional claims in published maps and institutional affiliations.

Copyright: (c) 2021 by the authors. Licensee MDPI, Basel, Switzerland. This article is an open access article distributed under the terms and conditions of the Creative Commons Attribution (CC BY) license (https:/ / creativecommons.org/licenses/by/ $4.0 /)$.

\begin{abstract}
The study aimed to identify a moderate degree of Ce addition to improve the toughness in the simulated coarse-grained heat-affected zone (CGHAZ) of high-strength low-alloy steels, based on the effect of the Ce content on particle characteristics, microstructure and impact toughness. Three steels with 0.012 wt. $\%, 0.050$ wt.\% and $0.086 \mathrm{wt} . \%$ Ce content were subjected to $100 \mathrm{~kJ} / \mathrm{cm}$ heat input in their thermal welding cycles. The particles and microstructures in the simulated CGHAZ of each steel were characterized and the impact-absorbance energy levels were measured at $-20{ }^{\circ} \mathrm{C}$. The results indicated that $\mathrm{Ce}_{2} \mathrm{O}_{2} \mathrm{~S}$ inclusion compounds were gradually modified to CexSy-CeP and $\mathrm{CeP}$ with the increasing of the Ce content. A higher fraction of acicular ferrite was formed in the 0.012 wt.\%-Ce-treated steel due to the lower mismatch between $\mathrm{Ce}_{2} \mathrm{O}_{2} \mathrm{~S}$ and $\alpha$-Fe. Furthermore, a lower fraction of M-A constituent was obtained in the $0.012 \mathrm{wt} \%$-Ce-treated steel. As a result, superior toughness and a typical amount of ductile fracture were detected in the simulated CGHAZ of the 0.012 wt.\%-Ce-treated steel. Compared with the 0.012 wt.\%-Ce-treated steel, a smaller prior austenite grain was observed in the $0.086 \mathrm{wt}$. $\%$-Ce-treated steel because of the segregation of CeP at the grain boundary. However, the larger size and density of $\mathrm{CeP}$ led to poor toughness in the CGHAZ of the $0.086 \mathrm{wt}$ \% $\%$-Ce-treated steel.
\end{abstract}

Keywords: HSLA steels; cerium; microstructure; grain refinement; impact toughness

\section{Introduction}

High-strength low-alloy (HSLA) steel is extensively applied in pressure vessels, oil and gas pipelines, offshore structures, bridges and building beams, due to its outstanding combination of high strength, high toughness, and good weldability, which is achieved through optimization of the alloy design in conjunction with thermo-mechanical processing [1-3]. In recent years, HSLA steel has generally utilized high-heat input welding for reducing costs and increasing welding efficiency. However, it induces the coarsening of austenite grains and microstructure transformation, degrading the toughness of the coarse-grained heat-affected zone (CGHAZ) in HSLA steels [4]. Thus, improvement of the toughness in the CGHAZ of HSLA steels that have endured high-heat input welding has been the subject of considerable research.

Extensive studies focused on the improvement of the toughness in the CGHAZ of steels have been carried out. Grain refinement is one approach that is used to solve this problem [5-7]. Previous studies showed that the second phase particles can effectively pin the grain boundary, thereby refining the prior austenite grain [6]. The pinning force mainly depends on the characteristics of the second phase particles. The presence of an abundance of fine and dispersed particles is more helpful in terms of inhibiting the 
growth of austenite grain during the thermal cycles of welding [7]. Furthermore, acicular ferrite $(\mathrm{AF})$ is also the microstructure that is desired in order to improve the toughness in the CGHAZ of steels [8,9]. The chaotic AF plates nucleate on intragranular inclusion compounds and form a fine-grained interlocking microstructure in the simulated CGHAZ of steel. They can effectively divide prior austenite grains into several regions and retard crack propagation, leading to the absorption of more energy during Charpy V-notch impact tests [10]. The martensite-austenite (M-A) constituent also has a profound influence on the impact toughness in CGHAZ [11,12]. Cracks usually nucleate at the interface between the $\mathrm{M}-\mathrm{A}$ constituent and the matrix and then extend into the substrate. In general, the impact toughness of the CGHAZ in HSLA steels decreases with the increasing of the fraction of M-A content, especially for hard, blocky M-A constituent [8].

To improve the toughness of CGHAZ, oxide metallurgy technology has been proposed, which aims to utilize fine and dispersed inclusion compunds in order to inhibit the growth of austenite grain and to induce the nucleation of AF. Numerous studies have reported the effect of Ti and $\mathrm{Mg}$ on the toughness of CGHAZ [4,6,13-15]. It was pointed out that the inclusion of $\mathrm{Ti}_{2} \mathrm{O}_{3}$ or $\mathrm{Ti}_{2} \mathrm{O}_{3}$ with an outer layer of $\mathrm{MnS}$ represents the most effective means of nucleating AF due to the formation of an Mn-depleted zone. This contributes to the promotion of $\mathrm{AF}^{\prime} \mathrm{s}$ formation and the improvement of the toughness in the CGHAZ of steel [14]. Furthermore, the fine $\operatorname{Ti}(\mathrm{C}, \mathrm{N})$ precipitate can inhibit the growth of austenite grain on the basis of the grain boundary pinning effect [16]. However, Ti oxides are easy to gather and develop. Therefore, the addition of $\mathrm{Mg}$ into steel was proposed as a means of further refining and dispersing Ti oxides, and simultaneously enabling the formation of Mg-Ti complex oxides that still maintain the capacity for AF nucleation [15]. However, the yield of $\mathrm{Mg}$ that possesses a high vapor pressure and a low boiling point $\left(1090^{\circ} \mathrm{C}\right)$ is extremely low in molten steel.

In recent years, the application of rare earth (RE) in HSLA steel has attracted considerable attention. The main reason for this is that the addition of a certain amount of RE can play a significant role in the cleaning, inclusion compound modification and micro-alloying of molten steel. Compared with $\mathrm{Mg}$ treatment, RE possesses a high boiling point (more than $3000{ }^{\circ} \mathrm{C}$ ) and great solubility in liquid steel, which creates good conditions for its application in steelmaking. Furthermore, RE exhibits a strong affinity with $\mathrm{O}$ and $\mathrm{S}$. It can react with them to form spherical RE oxides and RE sulfides with high melting points (over $1600{ }^{\circ} \mathrm{C}$ ) [17]. These RE inclusion compounds have a low misfit value with ferrite, which promotes the nucleation of AF [18]. Meanwhile, the excess addition of RE can lead to the formation of REPs or REAs [19], which contributes to the decreasing of the segregation of $\mathrm{P}$ or As at the grain boundary. However, this also causes a problem in terms of the accumulation and growth of inclusion compounds [20]. Therefore, the addition of Ce should be controlled by being kept at a certain content level. It is well known that the characteristics of RE inclusion compounds vary at different RE content levels [21,22]. However, the role of the RE content on the inclusion characteristic, microstructure and toughness in the CGHAZ of HSLA steel is not well understood, and in-depth study is needed.

Thus, the present work was conducted to explore the particle and microstructural characteristics in a simulated CGHAZ of HSLA steels with different Ce contents. The characteristics of particles-and their subsequent effects on the microstructural evolution and impact toughness in the simulated CGHAZ of high-Ce steels under high-heat input thermal cycles-were also studied and compared with those of their low-Ce steel counterparts.

\section{Materials and Methods}

The raw materials used in this work were commercial HSLA steel $(0.06$ mass $\%$ C, 0.25 mass\% Si, 1.564 mass\% Mn, 0.015 mass\% P, 0.002 mass\% S, 0.039 mass\% Als, 0.0017 mass \% T.O, 0.004 mass\% T.N, where Als denotes acid-soluble Aluminum in steel), and cerium rods (>99.9 mass $\%$ purity).

Experiments were conducted in a high frequency induction furnace with an $\mathrm{Al}_{2} \mathrm{O}_{3}$ crucible. Firstly, argon gas was blown through the furnace ( $99.999 \%$ purity) to maintain an 
inert working atmosphere of the chamber. The raw steel samples were directly placed in the $\mathrm{Al}_{2} \mathrm{O}_{3}$ crucible and melted at $1873 \mathrm{~K}$. Next, the cerium rods of different quality levels were added to different batches of molten steel. To avoid the oxidation of the cerium rods, they were wrapped with an iron sheet before being added to the batches. An oxygen-nitrogen analyzer (LECO-TC500), a carbon-sulfur analyzer (CS-8800) and ICP-AES (DGS-III) were used to analyze the chemical compositions of the experimental steels. Three steels with $0.012,0.050$ and 0.086 wt.\% Ce content were obtained, and were denoted as C1, C2 and C3 steel, respectively. The chemical compositions of the investigated steels are listed in Table 1.

Table 1. Chemical compositions of the investigated steels (wt.\%).

\begin{tabular}{ccccccccccccc}
\hline Samples & $\mathbf{C}$ & $\mathbf{M n}$ & $\mathbf{A l}$ & $\mathbf{S i}$ & $\mathbf{T i}$ & $\mathbf{N b}$ & $\mathbf{C r}$ & $\mathbf{C e}$ & $\mathbf{P}$ & $\mathbf{S}$ & $\mathbf{O}$ & $\mathbf{N}$ \\
\hline C1 & 0.05 & 1.62 & 0.038 & 0.26 & 0.023 & 0.065 & 0.25 & 0.012 & 0.012 & 0.0019 & 0.0015 & 0.0028 \\
C2 & 0.05 & 1.58 & 0.041 & 0.28 & 0.019 & 0.064 & 0.26 & 0.050 & 0.011 & 0.0013 & 0.0019 & 0.0031 \\
C3 & 0.05 & 1.63 & 0.053 & 0.28 & 0.021 & 0.063 & 0.25 & 0.086 & 0.011 & 0.0010 & 0.0020 & 0.0035 \\
\hline
\end{tabular}

The ingots were reheated to $1250 \pm 20^{\circ} \mathrm{C}$ and forged into a cuboid with a crosssection of $15 \mathrm{~mm} \times 15 \mathrm{~mm}$. Subsequently, the samples were machined into a cuboid with the dimensions of $5 \mathrm{~mm} \times 10 \mathrm{~mm} \times 55 \mathrm{~mm}$, and were then prepared for the thermal welding simulation, which carried out using a Gleeble 3800 . The simulated thermal cycle is schematically shown in Figure 1. The peak temperature for thermal cycle simulation was $1350{ }^{\circ} \mathrm{C}$, with a heating rate of $300{ }^{\circ} \mathrm{C} \mathrm{s}^{-1}$, and a holding time of $3 \mathrm{~s}$. The cooling time from 800 to $500{ }^{\circ} \mathrm{C}\left(\mathrm{t}_{8 / 5}\right)$ was $52.8 \mathrm{~s}$, which was approximately equivalent to the heat input of $100 \mathrm{~kJ} \cdot \mathrm{cm}^{-1}[15]$.

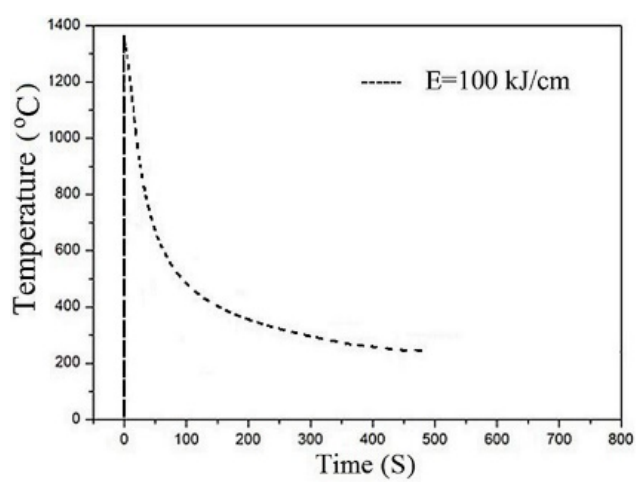

Figure 1. Schematic illustration of simulated thermal cycle of the CGHAZ.

After welding simulation, the Charpy V-notch impact toughness of the specimens with dimensions of $5 \mathrm{~mm} \times 10 \mathrm{~mm} \times 55 \mathrm{~mm}$ was then tested at $-20^{\circ} \mathrm{C}$. The microstructure and particle characteristics were observed using an optical microscope (Olympus BM51) and a Nova 400 Nano field scanning electron microscope (FE-SEM). The metallographic specimens were polished and etched in 4 vol.- $\%$ nital solution. The particles in the simulated CGHAZ were analyzed by SEM and transmission electron microscopy (TEM) with energy-dispersive spectroscopy (EDS). The TEM samples were thinned mechanically to $0.06 \mathrm{~mm}$, and then a twin-jet electropolisher was used for further thinning (5\% perchloric acid, $25 \%$ glycerol and $70 \%$ ethanol at $10{ }^{\circ} \mathrm{C}$ at $45 \mathrm{~V}$ ). The samples were examined on a TEM-2011F operated at $200 \mathrm{keV}$. For electron backscattered diffraction (EBSD) analysis, the samples were electropolished with $5 \%$ perchloric acid and $95 \%$ alcohol at $25{ }^{\circ} \mathrm{C}$ at $28 \mathrm{~V}$. The orientation relationship and crystallographic grain size of the microstructures were determined using EBSD with a Philips XL30W/TMP SEM at $1000 \times$ magnification; the step size was $0.3 \mu \mathrm{m}$. 


\section{Results}

\subsection{Particle Analysis}

The characteristics of the particles in the investigated steels were analyzed via SEM and TEM combined with EDS. Figure 2a presents the SEM micrographs and corresponding EDS mapping images of the inclusion compounds in the $\mathrm{C} 1$ steel. They indicate a completely overlapped distribution of $\mathrm{Ce}, \mathrm{O}$ and $\mathrm{S}$ atoms, implying that the inclusion compounds in the $\mathrm{C} 1$ steel were $\mathrm{Ce}_{2} \mathrm{O}_{2} \mathrm{~S}$. However, the inclusion compounds of the $\mathrm{C} 2$ and $\mathrm{C} 3$ steels were $\mathrm{Ce}_{\mathrm{x}} \mathrm{S}_{\mathrm{y}}-\mathrm{CeP}$ and $\mathrm{CeP}$, respectively (Figure $2 \mathrm{~b}, \mathrm{c}$ ). This reveals that the initially formed $\mathrm{Ce}_{2} \mathrm{O}_{2} \mathrm{~S}$ inclusion compounds were gradually transformed into $\mathrm{Ce}_{\mathrm{x}} \mathrm{S}_{\mathrm{y}}-\mathrm{CeP}$ and $\mathrm{CeP}$ with the increasing of the Ce content. Moreover, the number and size of the inclusion compounds in the investigated steels were automatically counted, using Image Pro-Plus software, by 50 random visual fields of the SEM at $1000 \mathrm{x}$ magnification. The size distributions of the inclusion compounds in the investigated steels are shown in Figure 3. It can be seen that the inclusion compounds of less than $2 \mu \mathrm{m}$ in size constituted approximately $78 \%$ of the $\mathrm{C} 1$ steel, but only about $50 \%$ and $48 \%$, respectively, of the C 2 and C 3 steel. Furthermore, the average sizes of the inclusion compounds in the C1, C2 and C3 steels were $1.5 \mu \mathrm{m}, 2.0 \mu \mathrm{m}$, and $2.5 \mu \mathrm{m}$, respectively, and the corresponding densities of the inclusion compounds were $91 \mathrm{~mm}^{-2}, 124 \mathrm{~mm}^{-2}$ and $265 \mathrm{~mm}^{-2}$, respectively (Table 2).
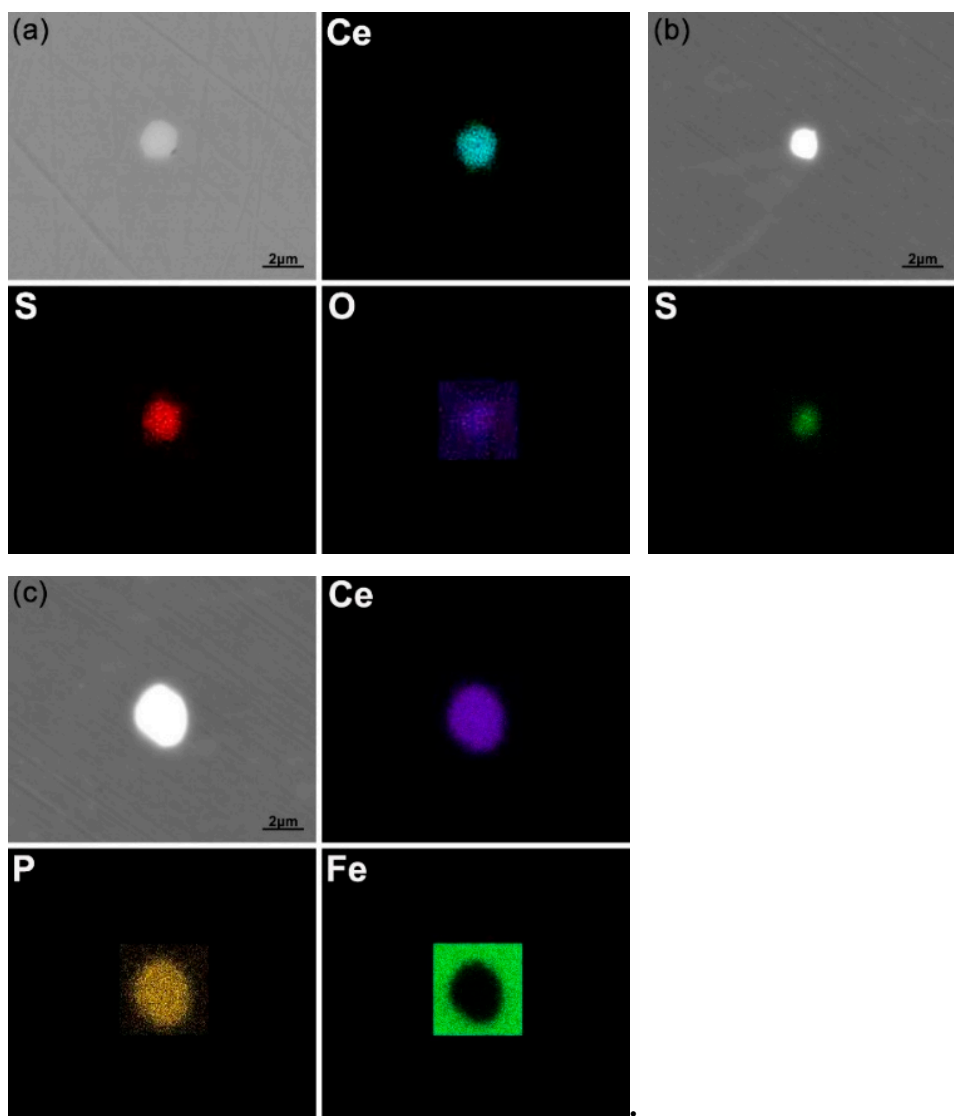

Ce
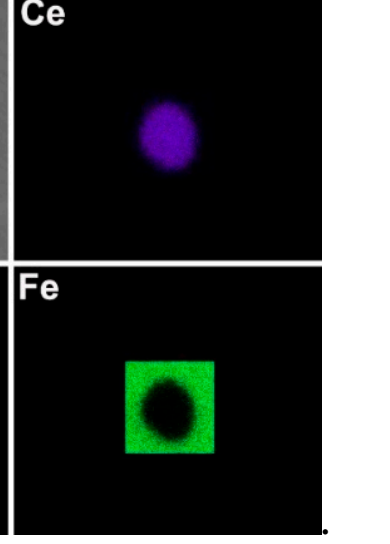
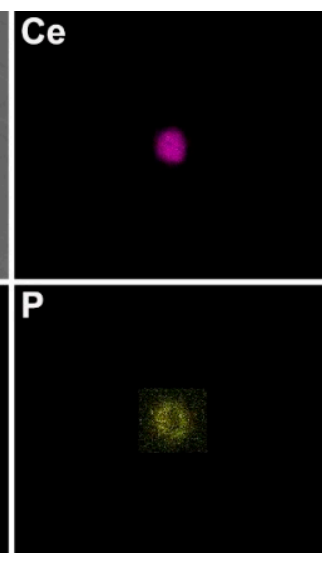

Figure 2. SEM micrographs and EDS mapping images of inclusion compounds in (a) C1, (b) C2 and (c) C3 steel. 


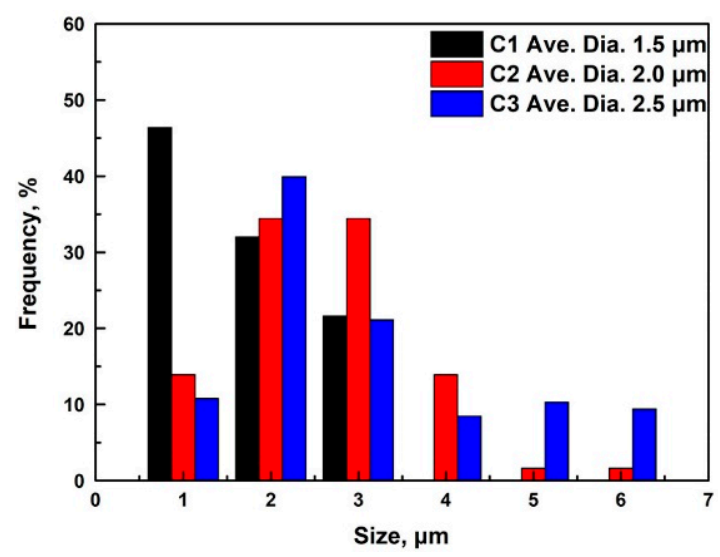

Figure 3. The size distributions of inclusion compounds in $\mathrm{C} 1, \mathrm{C} 2$ and $\mathrm{C} 3$ steels.

Table 2. The sizes and densities of inclusion compounds and precipitates in the investigated steels.

\begin{tabular}{ccccc}
\hline Samples & $\begin{array}{c}\text { Inclusion Compound } \\
\text { Size, } \boldsymbol{\mu m}\end{array}$ & $\begin{array}{c}\text { Inclusion Compound } \\
\text { Density, } / \mathbf{m m}^{\mathbf{2}}\end{array}$ & $\begin{array}{c}\text { Precipitate } \\
\text { Size, } \mathbf{~ n m}\end{array}$ & $\begin{array}{c}\text { Precipitate } \\
\text { Density, } / \mathbf{m m}^{\mathbf{2}}\end{array}$ \\
\hline C1 & $1.5 \pm 0.5$ & 91 & $36 \pm 8$ & $1.1 \times 10^{6}$ \\
C2 & $2.0 \pm 0.4$ & 124 & $51 \pm 5$ & $3.7 \times 10^{5}$ \\
C3 & $2.5 \pm 0.3$ & 265 & $80 \pm 7$ & $3.3 \times 10^{5}$ \\
\hline
\end{tabular}

Figure 4 presents the TEM micrographs and corresponding EDS results regarding the precipitates in the investigated steels. There were many nanoscale precipitates dispersed in the matrix. The EDS results show that the precipitates were $(\mathrm{Ti}, \mathrm{Nb})(\mathrm{C}, \mathrm{N})$ in all steels. It should be noted that the light elements $C$ and $N$ were hardly detected by the EDS due to their low relative atomic mass. Figure 5 shows that the precipitates of less than $40 \mathrm{~nm}$ in size constituted approximately $59 \%$ of the $\mathrm{C} 1$ steel, but only about $23 \%$ and $13 \%$, respectively, of the C2 and C3 steel. Table 2 shows that the average sizes of the precipitates in the C1, C2 and C3 steels were $36 \mathrm{~nm}, 51 \mathrm{~nm}$, and $80 \mathrm{~nm}$, respectively, and the corresponding densities of the precipitates were $1.1 \times 10^{6} \mathrm{~mm}^{-2}, 3.7 \times 10^{5} \mathrm{~mm}^{-2}$ and $3.3 \times 10^{5} \mathrm{~mm}^{-2}$, respectively. This indicates that more precipitates of finer size were found in the $\mathrm{C} 1$ steel.

\subsection{Microstructural Characteristic in the Simulated CGHAZ}

Figure 6 presents the optical and SEM micrographs representing the microstructural characteristics of the simulated CGHAZ of the investigated steels. The final microstructures, after the thermal cycles, consisted predominantly of BF (red arrows) and a small proportion of AF (white arrows) in all steels. The BF nucleated on the grain boundaries and grew, in the form of sheaves, into the grain interior. The AF plates grew in different directions and were embedded in the BF sheaves. Furthermore, the average sizes of the prior austenite grains in all steels were counted by 15 random visual fields of the OM at 200 magnifications using Image Pro-Plus software. It was found that the average sizes of the prior austenite grains were $51.2 \mu \mathrm{m}, 40.4 \mu \mathrm{m}$ and $35.2 \mu \mathrm{m}$ in the C1, C2 and C3 steels, respectively. The fraction and mean length of the AF in all steels were automatically counted by 20 random visual fields of the $\mathrm{OM}$ at $500 \mathrm{x}$ magnification using Image Pro-Plus software. It was found that the fraction of AF in the C1 steel took up approximately $4.3 \%$; however, in the C2 steel, this value was about $1.2 \%$, and in the C 3 steel it was only about $0.2 \%$. The mean lengths of the AF were $6.1 \mu \mathrm{m}, 4.2 \mu \mathrm{m}$ and $3.9 \mu \mathrm{m}$ in the C1, C2 and C3 steels, respectively (Table 3). Figure $6 \mathrm{~g}$, i illustrate the distributions of M-A constituents in the CGHAZ of steels with different Ce contents. The quantitative results of the M-A constituents were also measured, for all steels, using twenty SEM images with $5000 \times$ magnification. The area fractions of M-A constituents in the CGHAZ of the C1, C2 and C3 steels were $5.3 \%, 6.8 \%$ and $8.1 \%$, respectively (Table 3). 

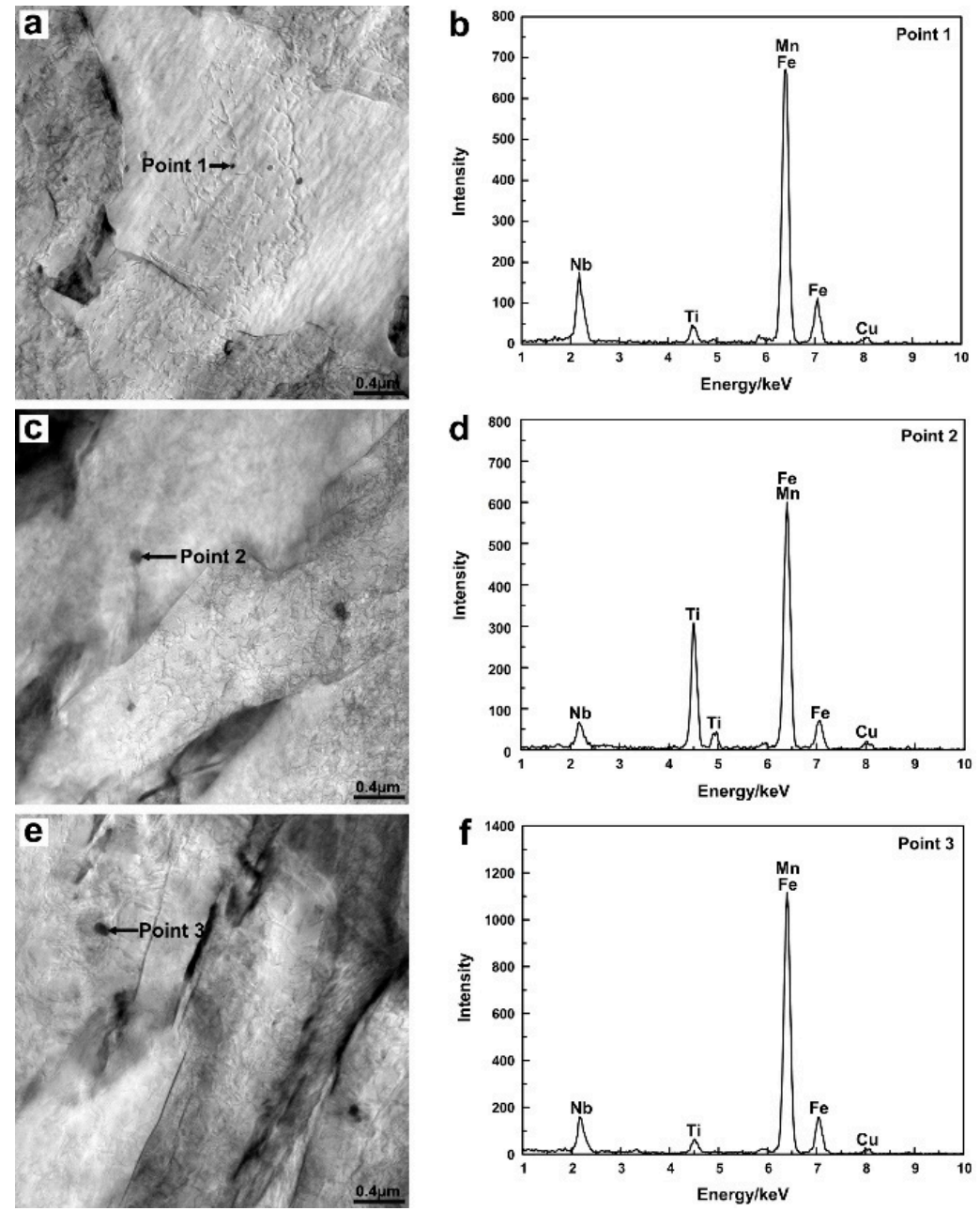

Figure 4. TEM micrographs of the precipitates and corresponding EDS analysis images of the precipitates in C1 (a,b), C2 (c,d) and C3 (e, f) steel.

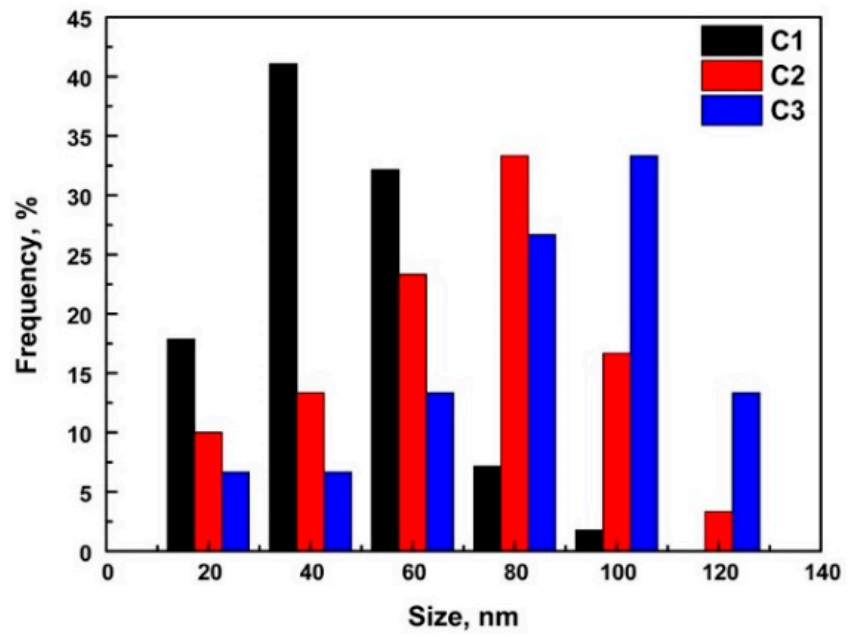

Figure 5. The size distribution of the precipitates in the investigated steels. 

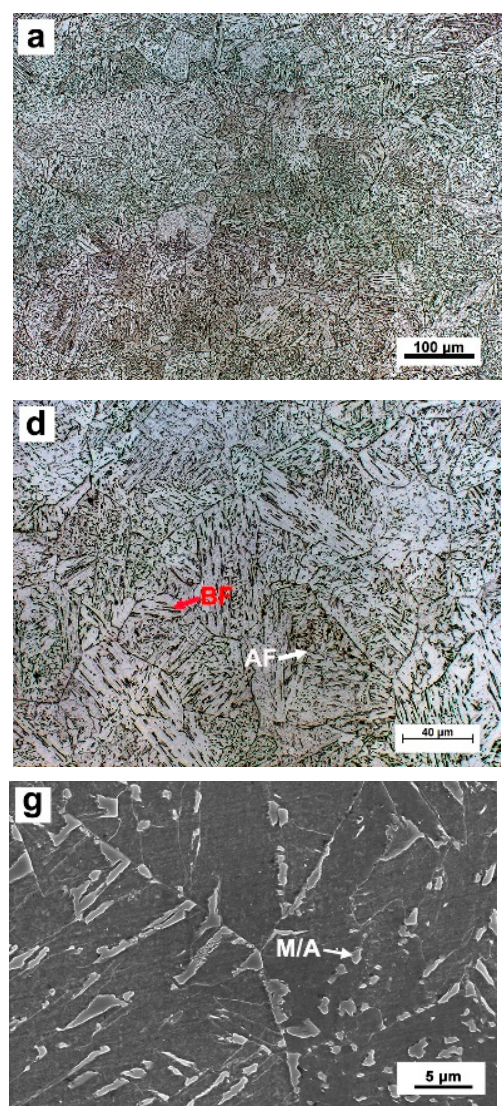
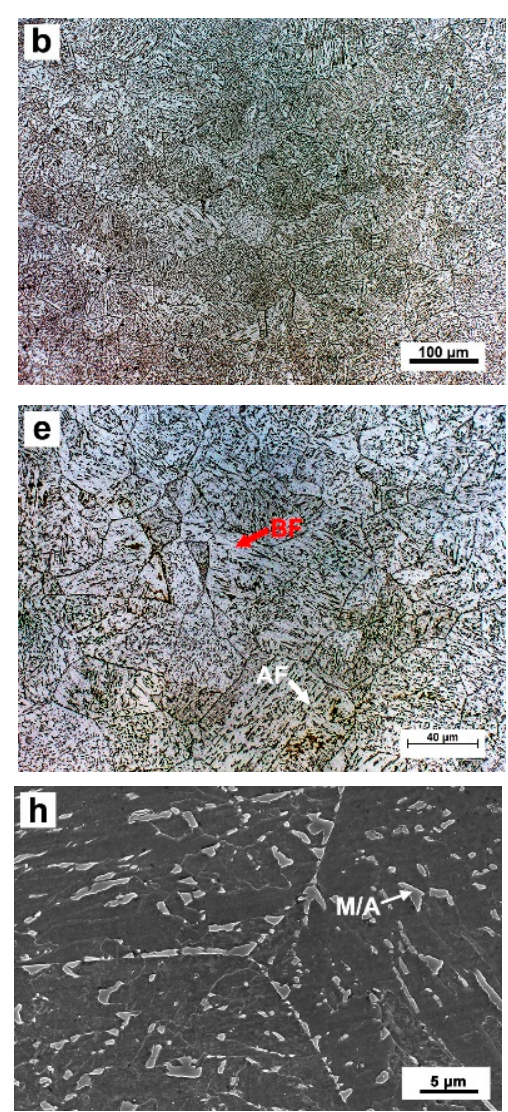
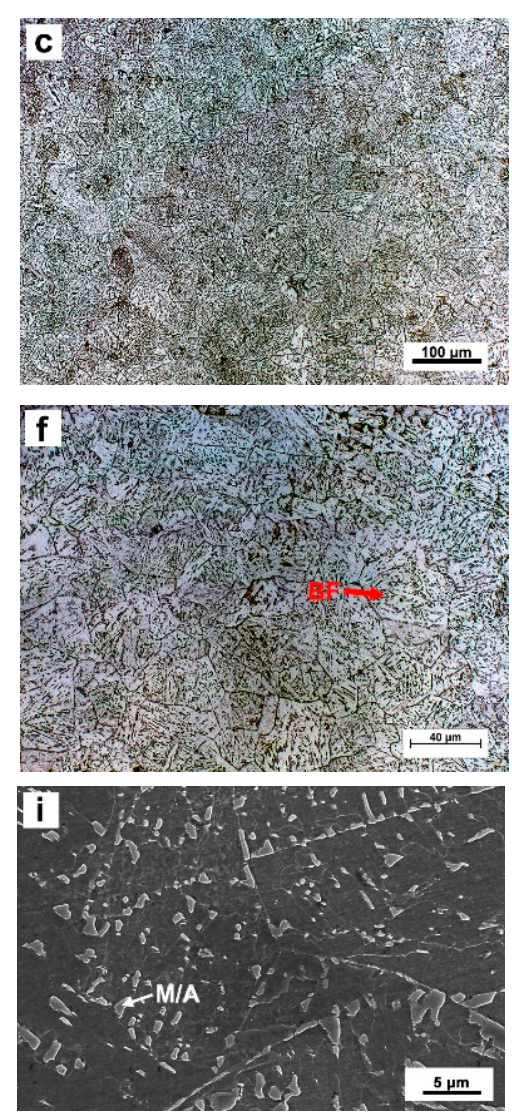

Figure 6. Optical and SEM micrographs in the simulated CGHAZ of C1 (a,d,g), C2 (b,e,h) and C3 (c,f,i) steels.

Table 3. Prior austenite grain size, length and fraction of acicular ferrite, and fraction of M-A constituent in the investigated steels.

\begin{tabular}{ccccc}
\hline Samples & $\begin{array}{c}\text { Mean Length of Prior } \\
\text { Austenite Grain, } \boldsymbol{\mu} \mathbf{m}\end{array}$ & $\begin{array}{c}\text { Mean Length of } \\
\mathbf{A F}, \boldsymbol{\mu m}\end{array}$ & $\begin{array}{c}\text { Fraction of AF, } \\
\mathbf{\%}\end{array}$ & $\begin{array}{c}\text { Fraction of M-A, } \\
\mathbf{\%}\end{array}$ \\
\hline C1 & $51.2 \pm 10$ & $6.1 \pm 1.3$ & 4.3 & 5.3 \\
C2 & $40.4 \pm 9$ & $4.2 \pm 0.8$ & 1.2 & 6.8 \\
C3 & $35.2 \pm 11$ & $3.9 \pm 0.6$ & 0.2 & 8.1 \\
\hline
\end{tabular}

\subsection{EBSD Analysis in the Simulated CGHAZ}

The misorientation and crystallographic grain size in the simulated CGHAZ of the investigated steels were studied by EBSD analysis. Figure 7c shows the EBSD orientation image maps in the simulated CGHAZ of the $C 1, C 2$ and $C 3$ steels, respectively. The different BF sheaves are represented by different colors and characterized by high angle grain boundaries between the sheaves. The BF plates in the same sheaf are represented by similar colors, indicating that those BF plates in the sheaf are characterized by low angle grain boundaries. This observation is attributed to the misorientation between variants of ferrite grain formed in the same austenite grain in low carbon steels according to the Kurdjumov-Sachs (K-S) or Nishiyama-Wasserman (N-W) orientation relationships [23]. AF grains that have $\mathrm{K}-\mathrm{S}$ orientation relationships with prior austenite grain maintain high misorientation with neighboring AF and BF plates [7]. 

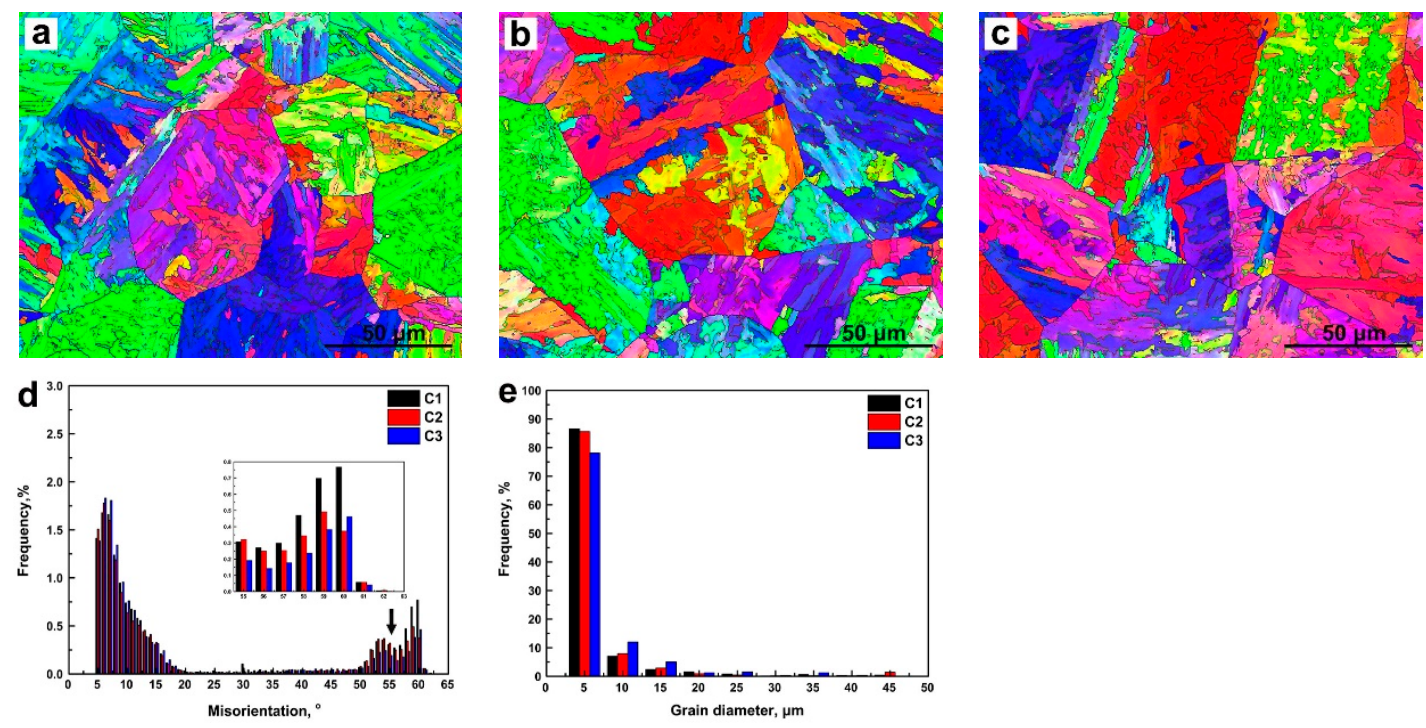

Figure 7. Orientation maps of bcc phases in the simulated CGHAZ of (a) C1, (b) C2 and (c) C3 steels, respectively. Statistical distribution of (d) grain angles between adjacent grains and (e) crystallographic grain size of simulated CGHAZ in the investigated steels.

Figure $7 \mathrm{~d}$ presents the distribution of the grain boundary misorientation angles between adjacent grains in the simulated CGHAZ of the investigated steels. It suggests that the low-angle grain boundaries with misorientation below $15^{\circ}$ accounted for the majority of the misorientation, and a few high-angle grain boundaries from $50^{\circ}$ to $62^{\circ}$ also existed in the matrix. These high-angle grain boundaries were the boundaries between acicular ferrite and bainite or the boundaries between bainite packets. The frequency of high-angle grain boundaries in the simulated CGHAZ of the $\mathrm{C} 1$ steel was higher than that of the $\mathrm{C} 2$ and C3 steels, implying that a higher fraction of AF formed in the C1 steel. Figure 7e shows the statistical distribution of the crystallographic grain size. In the present work, the large crystallographic misorientation threshold was estimated to be $15^{\circ}$. This means that the boundaries with misorientations larger than $15^{\circ}$ could be regarded as the boundaries of two crystallographic grains [20]. The mean equivalent diameters of crystallographic grain sizes in the simulated CGHAZ of the C1, C2 and C 3 steels were $3.5 \mu \mathrm{m}, 3.6 \mu \mathrm{m}$ and $4.5 \mu \mathrm{m}$, respectively (Table 4 ).

Table 4. Grain size and impact toughness of the investigated steels.

\begin{tabular}{ccc}
\hline Samples & $-\mathbf{2 0}{ }^{\circ} \mathbf{C}$ Absorbed Energy, $\mathbf{~}$ & Crystallographic Grain Size, $\boldsymbol{\mu m}$ \\
\hline C1 & $105 \pm 10$ & 3.5 \\
C2 & $80 \pm 15$ & 3.6 \\
C3 & $24 \pm 6$ & 4.5 \\
\hline
\end{tabular}

\subsection{Impact Toughness and Fractured Surface Characteristics in the Simulated CGHAZ}

The impact toughness levels of the simulated CGHAZ in three samples at $-20{ }^{\circ} \mathrm{C}$ are presented in Table 4. It can be seen that the impact toughness of three steels decreased with the increasing of the Ce content. The mean absorbed energy amounts in the simulated CGHAZ of the C1, C2 and C 3 steels were $105 \mathrm{~J}, 80 \mathrm{~J}$ and $24 \mathrm{~J}$, respectively. Figure 8 shows the fractographic features of the impact tested specimens. There were significant differences in fracture between the three specimens. In the $\mathrm{C} 1$ steel, the fracture surface consisted of abundant dimples, suggesting a typical ductile fracture mechanism (Figure 8a). Figure $8 b$ shows the fracture surface of the $\mathrm{C} 2$ steel. It can be observed that two regions included dimples and river patterns that coexisted on the impact-fractured surfaces, exhibiting a typical combination of ductile and quasi-cleavage fracture mechanisms. However, the fracture surface of the $\mathrm{C} 3$ steel was completely composed of river patterns (Figure 8c), which 
was regarded as a typical quasi-cleavage fracture mechanism. These results indicated that the fracture surface of the sample was consistent with the corresponding toughness value.
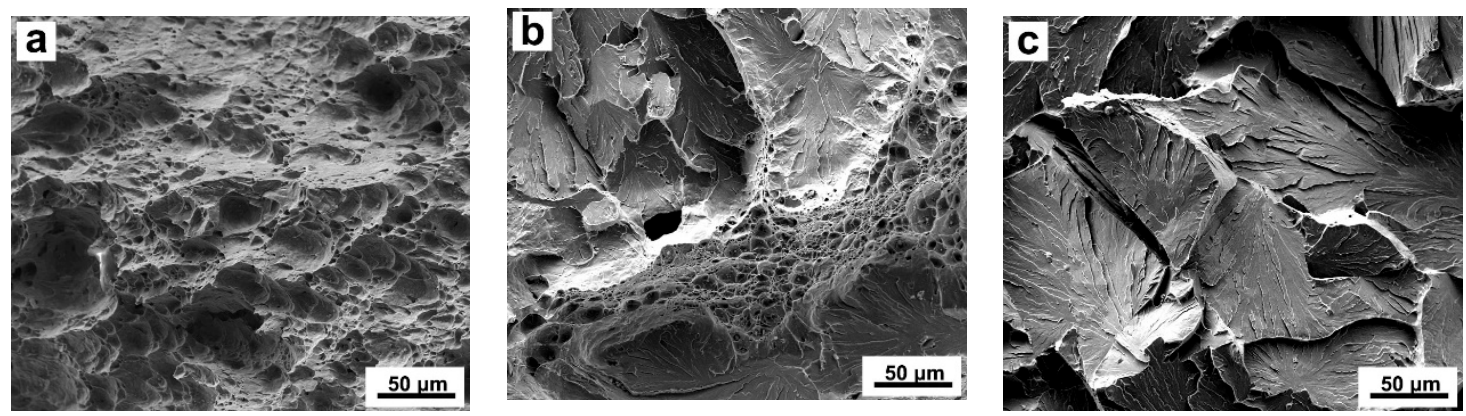

Figure 8. SEM fractographs showing fracture surface of C1 (a), C2 (b) and C3 (c) steels.

\section{Discussion}

\subsection{The Effect of Ce Content on Grain Refinement}

It is recognized that particles play an important role in grain refinement due to the grain boundary pinning effect. The pinning force depends on the characterization of particles. The fine and dispersed particles have stronger pinning forces that inhibit the growth of austenite grains $[6,13,24]$. In this study, the precipitates in all steels were $(\mathrm{Ti}, \mathrm{Nb})(\mathrm{C}, \mathrm{N})$. They gradually increased in size but decreased in density when the Ce content increased from $0.012 \mathrm{wt} . \%$ to $0.086 \mathrm{wt} . \%$ (Table 2). According to Zener's equation [25], the size of the austenite grain in the $\mathrm{C} 1$ steel should be smaller due to the finer and more dispersed precipitates, as other references reported [15,26]. However, finer austenite grain was obtained in the $\mathrm{C} 3$ steel. The reason behind this could be attributed to the inclusion compound characteristics of the $\mathrm{C} 3$ steel.

In the $\mathrm{C} 3$ steel, the inclusion compound was $\mathrm{CeP}$ rather than the more common $\mathrm{Ce}$ sulfide or oxysulfide found in the $\mathrm{C} 1$ and $\mathrm{C} 2$ steels because of the addition of excess Ce. Furthermore, the size and density of the inclusion compounds in the $\mathrm{C} 3$ steel were larger than those of the $\mathrm{C} 1$ and $\mathrm{C} 2$ steels. It is well known that residual elements such as $\mathrm{P}$ are unavoidable and difficult to remove in current steelmaking processes. They are generally segregated at the grain boundary, resulting in intergranular embrittlement [27]. In the C3 steel, the formation of $\mathrm{CeP}$ could decrease the grain boundary segregation of $\mathrm{P}$ and relieve the embrittlement behavior. Figure 9 shows the SEM micrograph and corresponding EDS analysis of the inclusion compounds on the grain boundary in C3 steel. It indicated that some finer $\mathrm{CeP}$ were formed at the grain boundary in the $\mathrm{C} 3$ steel. It was also conducive to the grain refinement. These results may represent the cause of the austenite grain in the $\mathrm{C} 3$ steel being smaller than that in the $\mathrm{C} 1$ and $\mathrm{C} 2$ steels.
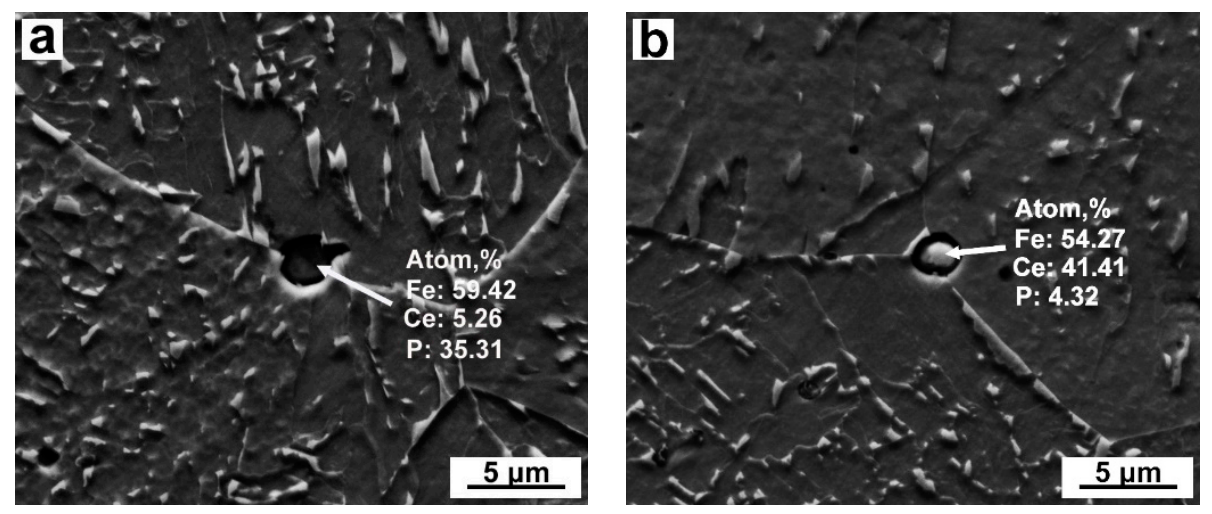

Figure 9. $(\mathbf{a}, \mathbf{b})$ SEM micrograph and corresponding EDS analysis of the inclusion compounds on the grain boundary in C3 steel. 


\subsection{Effect of Ce Content on Impact Toughness and the Formation of Acicular Ferrite}

Extensive works have indicated that inclusion compounds play an important role in the nucleation of AF. There are two mechanisms through which inclusion compounds induce AF nucleation - the formation of the element-depleted zone around the inclusion compounds, and the reduced interfacial energy between the ferrite and the inclusion compounds $[13,28,29]$. The Mn-depleted zone can be formed by the precipitation of MnS or/and the diffusion of Mn atoms into the vacancy of Ti oxide due to the lowering of the Mn content in the vicinity of the inclusion compounds [28,29]. Mn acts as an austenite stabilizer, and the formation of an Mn-depleted zone increases the phase transformation temperature and driving energy for AF nucleation, thereby promoting the formation of AF grains. Meanwhile, if the lattice relationship between ferrite and inclusion compounds is coherent, the inclusion compounds could also be effective in the nucleation of AF due to the low interfacial energy reducing the resistance of nucleation [30].

In this study, the inclusion compounds in the $\mathrm{C} 1, \mathrm{C} 2$ and $\mathrm{C} 3$ steels were $\mathrm{Ce}_{2} \mathrm{O}_{2} \mathrm{~S}$, $\mathrm{Ce}_{\mathrm{x}} \mathrm{S}_{\mathrm{y}}-\mathrm{CeP}$ and $\mathrm{CeP}$, respectively. The Mn-depleted zone could not be formed due to the absence of $\mathrm{MnS}$ and Ti oxide in the inclusion compounds of the investigated steels. Taking into account the interfacial energy between the ferrite and the inclusion compounds, the disregistries between the $\mathrm{Ce}$ and $\alpha$-Fe inclusion compounds were calculated using Bramfitt's Equation (1) [31], as follows:

$$
\delta_{(h k l)_{n}}^{(h k l)_{s}}=\sum_{i=1}^{3} \frac{\left|d[u v w]_{s}^{i} \cdot \cos \theta-d[u v w]_{n}^{i}\right|}{3 d[u v w]_{n}^{i}} \times 100
$$

where $s$ stands for the substrate (nucleating agent) and $n$ is the nucleated solid; ( $h k l) s$ is a low-index plane of the substrate (nucleating agent), and [uvw]s is a low-index direction in $(h k l)_{s} ;(h k l) n$ is a low-index plane in the nucleated solid, and [uvw] $n$ is a low-index direction in $(h k l) n ; d[u v w] n$ is the interatomic spacing along [uvw]n; $d[u v w] s$ is the interatomic spacing along [uvw]s; $\theta$ is the angle between the [uvw]s and [uvw]n.

The lattice parameters and disregistries of $\mathrm{Ce}$ and $\alpha$-Fe inclusion compounds at $912{ }^{\circ} \mathrm{C}$ (transformation temperature of $\gamma \rightarrow \alpha$ ) are shown in Table 5. During heterogeneous nucleation, nucleation with $\delta<12 \%$ is effective, and that with $\delta>12 \%$ is ineffective [31]. The disregistries between Ce and $\alpha$-Fe inclusion compounds were small $(<12 \%)$, at $912{ }^{\circ} \mathrm{C}$ (Table 5), indicating that they all contributed to the promotion of $\mathrm{AF}^{\prime} \mathrm{s}$ formation. However, the $\mathrm{Ce}_{2} \mathrm{O}_{2} \mathrm{~S}$ could be more advantageous, in terms of inducing AF nucleation, than $\mathrm{CeP}$ and $\mathrm{Ce}_{\mathrm{x}} \mathrm{S}_{\mathrm{y}}$ based on their lower mismatch $(\delta)$ with $\alpha$-Fe. This is in consonance with the experimental results showing that a higher fraction of $\mathrm{AF}$ was formed in the $\mathrm{C} 1$ steel (Table 3). Previous studies have indicated that AF plates usually nucleate on intragranular inclusion compounds and grow in different directions. This maintains high misorientation $\left(50-60^{\circ}\right)$ with neighboring AF and BF plates, effectively dividing the coarsened austenite grain into several small regions, and thereby refining the grain and improving the toughness of the CGHAZ in steel. In this study, the formation of a higher fraction of AF in the C1 steel contributed to the microstructure having finer crystallographic grain size (Table 4). Meanwhile, it also made crack propagation more difficult during the $-20{ }^{\circ} \mathrm{C}$ Charpy $\mathrm{V}$-notch impact test, resulting in a superior toughness and a typical ductile fracture obtained in the $\mathrm{C} 1$ steel (Table 4).

Table 5. Disregistry between $\mathrm{Ce}$ and $\alpha$-Fe inclusion compounds.

\begin{tabular}{ccccc}
\hline Inclusion & Lattice Type & Lattice Constant $\mathbf{d} / \mathbf{n m}$ & $\mathbf{d} / \mathbf{d} \boldsymbol{\alpha}-\mathbf{F e}$ & $\boldsymbol{\delta} / \%$ \\
\hline $\mathrm{Ce}_{2} \mathrm{O}_{2} \mathrm{~S}$ & Cubic & 0.4004 & 1.395 & 0.2 \\
$\mathrm{Ce}_{2} \mathrm{~S}_{3}$ & Cubic & 0.8749 & 3.048 & 1.7 \\
$\mathrm{CeS}$ & Cubic & 0.5766 & 2.013 & 0.5 \\
$\mathrm{Ce}_{3} \mathrm{~S}_{4}$ & Cubic & 0.8630 & 3.007 & 0.4 \\
$\mathrm{CeP}$ & Cubic & 0.5920 & 2.063 & 3.2 \\
\hline
\end{tabular}


Furthermore, the M-A constituent, as an initiation site for a crack, is a negative factor for the improvement of the toughness of CGHAZ [11,12,32]. The hard and brittle M-A constituents, transformed by the untransformed austenite with enriched carbon, were scattered in the bainite packets or between the boundary of bainite packets in the simulated CGHAZ. The microcrack thus formed easily at the boundaries between the M-A constituent and the ferrite matrix. Yang et al. [33] indicated that with the increasing of the rare earth content in steel, the temperature of Ar1 can gradually decrease and the temperature of Ms can increase. That makes the continuous cold transformation curve (CCT) move to the lower right, resulting in more untransformed austenite being formed and, subsequently, more M-A constituent being generated with the decreasing of the temperature. This is consistent with the experiment results showing that the fraction of the M-A constituent in the C3 steel was larger than that in the C1 and C2 steels due to the higher Ce content (Table 3).

To summarize, the superior impact toughness in the CGHAZ of the C1 steel was attributed to the fine-grained microstructure with a higher fraction of acicular ferrite and a lower fraction of the M-A constituent. Although finer austenite grain was obtained in the $\mathrm{C} 3$ steel because of the formation of $\mathrm{CeP}$ at the grain boundary, poor impact toughness was observed due to the larger size and density of the CeP. If CeP can be well controlled and kept at a certain size and density, it will also contribute to the improvement of the toughness in the CGHAZ of steel.

\section{Conclusions}

1. With the increasing of the Ce content from 0.012 wt. $\%$ to 0.086 wt. $\%$, the $\mathrm{Ce}_{2} \mathrm{O}_{2} \mathrm{~S}$ inclusion compounds in the $\mathrm{C} 1$ steel were gradually modified to $\mathrm{Ce}_{\mathrm{x}} \mathrm{S}_{\mathrm{y}}-\mathrm{CeP}$ in the $\mathrm{C} 2$ steel and $\mathrm{CeP}$ in the $\mathrm{C} 3$ steel. The number and density of inclusion compounds also increased with the increasing of the Ce content.

2. Compared with $\mathrm{C} 2$ and $\mathrm{C} 3$ steels, the $\mathrm{Ce}_{2} \mathrm{O}_{2} \mathrm{~S}$ inclusion compounds in $\mathrm{C} 1$ steel were more conducive to inducing the formation of AF due to their lower mismatch with $\alpha-\mathrm{Fe}$, which contributed to the improvement of the toughness in the CGHAZ.

3. Smaller prior austenite grain was observed in the $\mathrm{C} 3$ steel because of the formation of $\mathrm{CeP}$ at the grain boundary. However, the impact toughness in the CGHAZ of the C3 steel decreased due to the larger size and density of the CeP.

4. The superior toughness in the simulated CGHAZ of the C1 steel was attributed to the formation of a fine-grained microstructure with a higher density of acicular ferrite grains and a lower fraction of M-A constituents.

Author Contributions: Conceptualization, X.W. and G.L.; methodology, X.W. and Y.C.; validation, X.W., K.W. and G.L.; formal analysis, Y.C.; investigation, Y.C.; resources, X.L., X.W. and F.Z.; data curation, Y.C.; writing—original draft preparation, Y.C.; writing-review and editing, Y.W., X.W., G.L. and Y.C.; supervision, X.W., G.L. and Y.C.; project administration, X.W. and G.L. All authors have read and agreed to the published version of the manuscript.

Funding: The authors gratefully acknowledge the support received from the National Natural Science Foundation of China (Grant No.: U20A20277), the Guangdong Basic and Applied Basic Research Foundation (Grant No.: 2019A1515011828, 2018A030313287), the University Innovation Team of the Department of Education of Guangdong Province (Grant No.: 2019GKCXTD005) and the Key projects of Hunan Provincial Department of Education (Grant No.: 19A126).

Data Availability Statement: The data presented in this study are available on request from the corresponding author.

Conflicts of Interest: The authors declare no conflict of interest. 


\section{References}

1. Hashemi, S.G.; Eghbali, B. Analysis of the formation conditions and characteristics of interphase and random vanadium precipitation in a low-carbon steel during isothermal heat treatment. Int. J. Miner. Metall. Mater. 2018, 3, 339-349. [CrossRef]

2. Xie, Z.; Shang, C.J.; Wang, X.; Wang, X.; Han, G.; Misra, R. Recent progress in third-generation low alloy steels developed under M3 microstructure control. Int. J. Miner. Metall. Mater. 2020, 27, 1-9. [CrossRef]

3. Gan, X.L.; Wan, X.L.; Zhang, Y.J.; Wang, H.H.; Li, G.Q.; Xu, G.; Wu, K.M. Investigation of characteristic and evolution of fine-grained bainitic microstructure in the coarse-grained heat-affected zone of super-high strength steel for offshore structure. Mater. Charact. 2019, 157, 109893. [CrossRef]

4. Zhang, Y.; Yang, J.; Liu, D.; Pan, X.Q.; Xu, L.Y. Improvement of impact toughness of the welding heat-affected zone in high-strength low-alloy steels through Ca deoxidation. Metall. Mater. Trans. A 2021, 52, 668-679. [CrossRef]

5. Tervo, H.; Kaijalainen, A.; Pallaspuro, S.; Anttila, S.; Mehtonen, S.; Porter, D.; Kömi, J. Low-temperature toughness properties of $500 \mathrm{MPa}$ offshore steels and their simulated coarse-grained heat-affected zones. Mater. Sci. Eng. A 2020, 773, 138719. [CrossRef]

6. Lin, C.K.; Su, Y.H.; Hwang, W.S.; Lin, G.R.; Kuo, J.C. On pinning effect of austenite grain growth in Mg-containing low-carbon steel. Mater. Sci. Technol. 2018, 34,1-11. [CrossRef]

7. Liu, Y.; Li, G.Q.; Wan, X.L.; Zhang, X.G.; Shen, Y.; Wu, K.M. Toughness improvement by Zr addition in the simulated coarsegrained heat-affected zone of high strength low-alloy steels. Ironmak. Steelmak. 2019, 46, 113-123. [CrossRef]

8. Liu, Y.; Li, G.Q.; Wan, X.L.; Wang, H.H.; Wu, K.M.; Misra, R.D.K. The role of $\mathrm{Cu}$ and $\mathrm{Al}$ addition on the microstructure and fracture characteristics in the simulated coarse-grained heat-affected zone of high-strength low-alloy steels with superior toughness. Mater. Sci. Technol. 2017, 33, 1750-1764. [CrossRef]

9. Xiong, Z.H.; Liu, S.L.; Wang, X.M.; Shang, C.J.; Li, X.C.; Misra, R.D.K. The contribution of intragranular acicular ferrite microstructural constituent on impact toughness and impeding crack initiation and propagation in the heat-affected zone (HAZ) of low-carbon steels. Mater. Sci. Eng. A 2015, 636, 117-123. [CrossRef]

10. Shim, J.; Cho, Y. Nucleation of intragranular ferrite at $\mathrm{Ti}_{2} \mathrm{O}_{3}$ particle in low carbon steel. Acta Mater. 1999, 47, $2751-2760$. [CrossRef]

11. Li, X.; Fan, Y.; Ma, X.; Subramanian, S.V.; Shang, C.J. Influence of Martensite-Austenite constituents formed at different intercritical temperatures on toughness. Mater. Des. 2015, 67, 457-463. [CrossRef]

12. Cui, J.J.; Zhu, W.T.; Chen, Z.Y.; Chen, L.Q. Microstructural Characteristics and Impact Fracture Behaviors of a Novel High-Strength Low-Carbon Bainitic Steel with Different Reheated Coarse-Grained Heat-Affected Zones. Metall. Mater. Trans. A 2020, 51, 1-11. [CrossRef]

13. Zou, X.D.; Sun, J.C.; Matsuura, H.; Wang, C. In situ observation of the nucleation and growth of ferrite laths in the heat-affected zone of EH36-Mg shipbuilding steel subjected to different heat inputs. Metall. Mater. Trans. B 2018, 49, 2168-2173. [CrossRef]

14. Shen, Y.; Wan, X.L.; Liu, Y.; Zheng, Z.L.; Wu, K.M. The significant impact of Ti content on microstructure-toughness relationship in the simulated coarse-grained heated-affected zone of high-strength low-alloy steels. Ironmak. Steelmak. 2018, 46, 584-596. [CrossRef]

15. Liu, Y.; Wan, X.L.; Li, G.Q.; Wang, Y.; Zheng, W.; Hou, Y.H. Grain refinement in coarse-grained heat-affected zone of Al-Ti-Mg complex deoxidised steel. Sci. Technol. Weld. Join. 2019, 24, 43-51. [CrossRef]

16. Liu, D.K.; Yang, J.; Zhang, Y.H.; Xu, L.Y. Effect of Mo content on nano-scaled particles, prior austenite grains and impact toughness of CGHAZ in offshore engineering steels. J. Iron Steel Res. Int. 2021. [CrossRef]

17. Adabavazeh, Z.; Hwang, W.S.; Su, Y.H. Effect of adding cerium on microstructure and morphology of Ce-based inclusions formed in low-carbon steel. Sci. Rep. 2017, 7, 46503. [CrossRef] [PubMed]

18. Song, M.M.; Song, B.; Xin, W.B.; Sun, G.L.; Song, G.Y.; Hu, C.L. Effects of rare earth addition on microstructure of C-Mn steel. Ironmak. Steelmak. 2015, 42, 594-599. [CrossRef]

19. Guo, F.; Lin, Q. Study on interaction between lanthanum and phosphor in purity steel. J. Rare Earth 2006, 24, 409-412.

20. Cao, Y.X.; Wan, X.L.; Hou, Y.H.; Liu, Y.; Song, M.M.; Li, G.Q. Comparative study on the effect of Y content on grain refinement in the simulated coarse-grained heat-affected zone of X70 pipeline steels. Micron 2019, 127, 102758. [CrossRef]

21. Yan, N.; Yu, S.; Ying, C. In situ observation of austenite grain growth and transformation temperature in coarse grain heat affected zone of Ce-alloyed weld metal. J. Rare Earth 2017, 35, 203-210. [CrossRef]

22. Cao, Y.X.; Wan, X.L.; Zhou, F.; Dong, H.Y.; Wu, K.M.; Li, G.Q. The critical influence of La content on the microstructure-toughness relationship in the simulated coarse-grained heat-affected zone of high-strength low-alloy steels. Metall. Res. Technol. 2021, 118, 212. [CrossRef]

23. Dere, G.E.; Sharma, H.; Petrov, R.H.; Sietsma, J.; Offerman, S.E. Effect of niobium and grain boundary density on the fire resistance of Fe-C-Mn steel. Scr. Mater. 2013, 68, 651-654. [CrossRef]

24. Wan, X.L.; Wu, K.M.; Nune, K.C.; Li, Y.; Cheng, L. In situ observation of acicular ferrite formation and grain refinement in simulated heat affected zone of high strength low alloy steel. Sci. Technol. Weld. Join. 2015, 20, 254-263. [CrossRef]

25. Manohar, P.A.; Ferry, M.; Chandra, T. Five decades of the Zener equation. ISIJ Int. 1998, 38, 913-924. [CrossRef]

26. Lei, X.W.; Zhou, S.B.; Huang, J.H. Austenite grain size prediction in the coarse-grained heat-affected zone of the developed Cu-free high-strength low-alloy hull structure steel. Metall. Mater. Trans. A 2020,11,1-12. [CrossRef]

27. Seah, M.P.; Spencer, P.J.; Hondros, E.D. Additive remedy for temper brittleness. Mater. Sci. Technol. 2013, 13, 307-314. [CrossRef] 
28. Shim, J.H.; Byun, J.S.; Cho, Y.W.; Oh, Y.J.; Lee, D.N. Mn absorption characteristics of $\mathrm{Ti}_{2} \mathrm{O}_{3}$ inclusions in low carbon steel. Scr. Mater. 2001, 44, 49-54. [CrossRef]

29. Hou, Y.; Zheng, W.; Wu, Z.; Li, G.Q.; Moelans, N.; Guo, M.X.; Khan, B.S. Study of Mn absorption by complex oxide inclusions in Al-Ti-Mg killed steels. Acta Mater. 2016, 118, 8-16. [CrossRef]

30. Koseki, T.; Thewlis, G. Overview inclusion assisted microstructure control in C-Mn and low alloy steel welds. Mater. Sci. Technol. 2013, 21, 867-879. [CrossRef]

31. Bramfitt, B.L. The effect of carbide and nitride additions on the heterogeneous hucleation behavior of liquid iron. Metall. Trans. 1970, 1, 1987-1995. [CrossRef]

32. Mohseni, P.; Solberg, J.K.; Karlsen, M.; Akselsen, O.M.; Østby, E. Cleavage fracture initiation at M-A constituents in intercritically coarse-grained heat-affected zone. Metall. Mater. Trans. A 2014, 45, 384-394. [CrossRef]

33. Yang, L.Y.; Wang, B.F.; Li, C.L.; Wang, Q. Effect of rare earth on microstructure and phase transformations point. J. Baotou Univ. Iron Steel Technol. 2004, 23, 45-47. 